\title{
UK launches inquiry into Clostridium difficile outbreak
}

England's Health Secretary launched a national inquiry June 14 into an outbreak of Clostridium difficile that has killed at least 25 patients and infected 565 more at 2 hospitals, and which may be linked to what Quebec officials have called an "epidemic" in their province.

Infection control experts at Stoke Mandeville Hospital in Aylesbury, England, are investigating whether the strain is the same virulent one responsible for outbreaks of the infection in Quebec, Alberta and parts of the US. At the Aylesbury hospital, 300 patients have been infected with $C$. difficile and 12 patients have died since 2003. The hospital team is liaising with counterparts in the US and Canada to share information and best practices on how to deal with the problem.

At the Royal Devon and Exeter in Devon, England, 265 patients have been infected and 13 have died between January and June 2005.

A government microbiologist told the New Zealand Herald that $\rightarrow$ the UK strain is similar to the  and the US. "But we have no idea how they are related or how the infection has been transmitted [to Britian]," said Brian Duerden, the chief inspector of mirobiology and hospital infection at the $\mathrm{Na}$ -

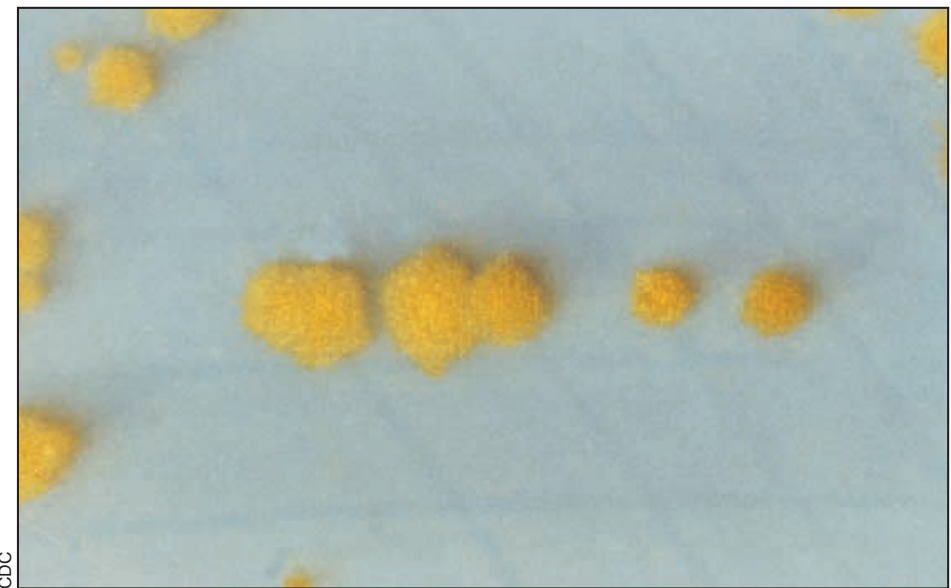

C. difficile is the most frequently identified cause of antibioticassociated diarrhea. tional Health Service (NHS).

In addition to the 2 hospitals, the UK Healthcare Commission, "will also be looking at the national picture and deciding whether we need to widen the scope of our investigations futher," says Anna Walker, head of the commission, which will carry out the investigation.

Dr. Andrew Kirk, director of infection prevention and control for the Buckinghamshire Hospital's NHS Trust, said the hospital administration is taking the issue extremely seriously. "We do however need to be realistic about the prevalence of these bacteria in our community and ensure that patients who acquire it are treated effectively and quickly to prevent any further spread."

C. difficile has long been a problem in the NHS, which has established a national $C$. difficile standards group to tackle the problem.

In 2004, there were 43672 positive reports for $C$. difficile in the UK (excluding Scotland), an increase of $23 \%$ from 2003. Much of the increase is thought to be due to improved reporting, which England made mandatory in April 2003.

Professor Mark Wilcox of the University of Leeds told the $C M A 7$ that each case of $C$. difficile costs the NHS between $\$ 9000$ and \$11 200. This could mean the infection costs the health service up to $\$ 486$ million per year.

The National Audit Office estimates there are 5000 deaths per year from nocosomial infection, and puts the combined costs to the NHS from all hospital-acquired infections at \$2.25 billion per year.

The UK announced new legislation last month to enforce stricter hygiene standards to combat hospital-acquired infections in all NHS bodies, facilities run by independent health care providers, and care homes in England.

Tackling health care associated infections is a top priority for the government, says Health Secretary Patricia Hewitt. "We want an effective inspection regime that can really make a difference and drive up standards of hygiene and infection control across the board."

"Hospitals which fail to meet standards in the Code will be issued with tough new improvement orders. If they continue to fail to come up to scratch, sanctions could be applied," she warned.

The government also launched a national "clean your hands" campaign that involves placing disinfectants in all clinical areas, providing promotional materials to staff and patients, and involving patients in improved hand hygiene.

Quebec invested \$20 million to improve hospital cleanliness earlier this year, following an epidemic of $C$. difficile. But Canada has not yet instituted compulsory reporting.

Hospital-acquired infections were a major election issue in the UK general election in May, with all 3 major parties pledging to increase investment in hospital hygiene.

The government has already spent \$152 million on improving hospital cleanliness since 2000. - Vittal Katikireddi, Edinburgh, Scotland 